Article

\title{
Performance Based Abstraction of Biomimicry Design Principles using Prototyping
}

\author{
Erin Rovalo * and John McCardle \\ Loughborough Design School, Loughborough University, Loughborough LE11 3TU, UK \\ * Correspondence: e.leitch@lboro.ac.uk
}

Received: 31 May 2019; Accepted: 12 July 2019; Published: 16 July 2019

check for

updates

\begin{abstract}
A key challenge faced by biomimicry practitioners is making the conceptual leap between biology and design, particularly regarding collaborating across these knowledge domains and developing and evaluating design principles abstracted from biology. While many tools and resources to support biomimicry design exist, most largely rely on semantic techniques supporting analogical translation of information between biology and design. However, the challenges of evaluation and collaboration are common in design practice and frequently addressed through prototyping. This study explores the utility of prototyping in the unique context of biomimicry by investigating its impact on the abstraction and transfer of design principles derived from biology as well as on cross-domain collaboration between biologists and designers. Following a survey exploring current practices of practitioners, in depth interviews provided detailed accounts of project experiences that leveraged prototyping. Four primary themes were observed: (1) Approximation; (2) The Prototyping Principle; (3) Synthesis and Testing; and (4) Validation. These themes introduce a unique abstraction and transfer process based on form-finding and collaborative performance evaluation in contrast to the widely accepted semantic language-based approaches. Our findings illustrate how designers and engineers can leverage a prototyping skillset in order to develop boundary objects between the fields of biology and design to navigate challenges uniquely associated with the biomimicry approach.
\end{abstract}

Keywords: biomimicry; biologically inspired design; prototyping; design practice; design by analogy; cross-domain knowledge transfer

\section{Introduction}

As designers and engineers increasingly look to biology as a source of analogous solutions [1], there is a need that grows in parallel for clearer biomimicry methods and techniques that make biological information accessible and useful to design and engineering challenges [2]. The biomimicry practitioner community includes a wide range of professions [3], including product and industrial designers [4], engineers [5], architects [6], materials scientists [7], and the biologists they collaborate with [8]. For the purpose of this research, 'designers and engineers' refers to those practitioners working in three-dimensional design at any scale as a convenient umbrella term. Practitioners are tasked with the analysis, evaluation, and mapping of information between biology and design or engineering in order to produce a design principle that can be transferred and applied to a solution [9-11]. These challenges are heightened in biomimicry compared to other forms of design by analogy due to the remote conceptual distance between biology and design that increases complexity and the resources required to employ this unique approach [12]. However, there is a rich body of knowledge on design techniques, specifically prototyping, to manage similar challenges of embodying and developing a design hypothesis, testing and evaluation, and collaboration between stakeholders [13-15] that could aid the development of biomimicry projects. This study explores how prototyping is currently being used by biomimicry practitioners to abstract, transfer, and aid collaboration between biologists and 
designers. We discuss a unique approach on how prototyping as a common practice of design can support some of the unique challenges of biomimicry.

Biomimicry, innovation inspired by nature [16], is a methodology for learning from strategies and mechanisms observed in biological forms, processes, and systems and applying them to solve a wide variety of potential challenges, including those of engineering and design [10]. Its premise is that the estimated 30-100 million species present today are the result of 3.8 billion years of evolution through natural selection that equates a rigorous "research and development" process resulting in a rich source of functionally analogous solutions demonstrating a high degree of novelty without the level of environmental degradation $[17,18]$ commonly observed in innovations resulting from the Industrial Revolution [19]. Biomimicry is an emerging field with indications of strong growth potential in industry [1] and academia [20]. Various descriptions of the methodology can be found in the literature and are similar in concept and in the use of function as a means for determining relevance of biological phenomena but have nuances in specificity and description among them [10,21-24]. Fayemi et al. [9] recently analysed various methodological descriptions and summarized the overarching steps of the process as (1) Problem Analysis; (2) Abstract Technical Challenge; (3) Transpose to Biology; (4) Identify Potential Biological Models; (5) Select Biological Models of Interest; (6) Abstract Biological Strategies; (7) Transpose to Technology; and (8) Implement and Test.

Biomimicry has been described as a form of design by analogy that draws on the far source knowledge domain of biology for its inputs [25]. All design by analogy requires some degree of conceptual or mental leaps [26], however biomimicry represents a particular cognitive challenge to its practitioners in that biology is such a far source of analogical solutions that it has very few attributes that can be directly mapped to a solution. In practice, the processing time required to address this challenge can increase the time and effort required to generate viable solutions that capture the benefits of biomimicry [12]. When a practitioner identifies a relevant biological model for their problem, the forms, materials, fabrication methods, behaviors, and scales observed in the biological model will not typically be directly applied to the solution. Rather it is the functional principle behind the biological mechanism, referred to as the biomimicry design principle, that the practitioner seeks and subsequently the appropriate means for emulating that principle. This task represents one of the most significant conceptual leaps of the process captured as the 'second gap' [27], or conceptual leap, with various associated challenges captured in Figure 1 and quantified with difficulty scores reported by current practitioners showing challenges related to abstraction of biological systems and communication across disciplines as being particularly difficult [3]. Because biological systems are inherently embedded in an interconnected context with other biological systems and use radically different materials and methods than designers and engineers [28], abstracting clear biomimicry design principles that have the potential for technological transfer can be a source of much confusion and frustration for practitioners that are frequently, though not always, stacking goals of both innovation and sustainability [29].

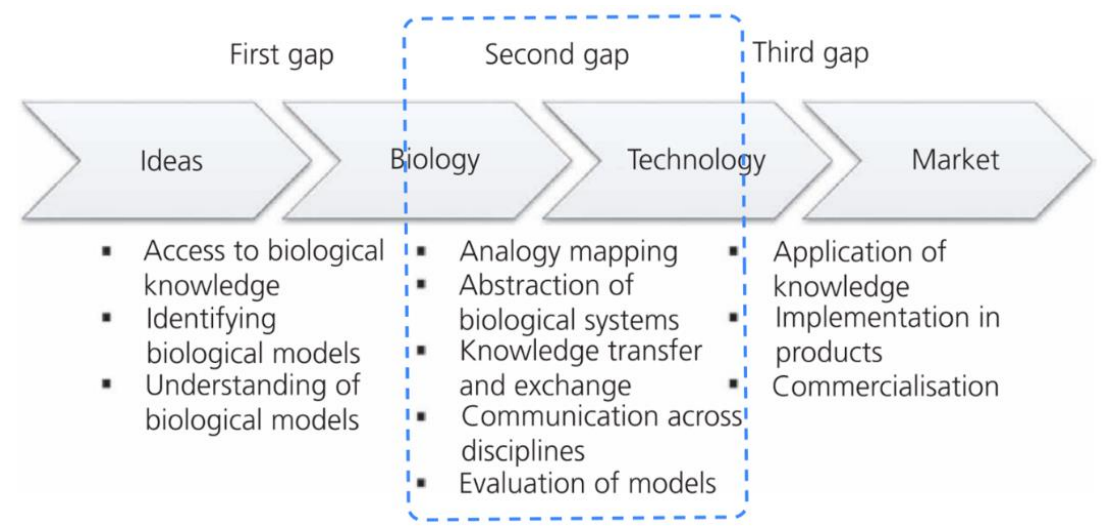

Figure 1. 'Gaps' (or conceptual leaps) in the biomimicry design process and their underlying challenges [27] with the 'second gap' outlined to indicate the area of focus for this study. 
While there is much ongoing research to aid the discovery of relevant biological models, there are fewer resources to aid the abstraction and transfer of biomimicry design principles to solutions. Abstraction is referring to the task of analyzing the biological reference and isolating the variables that are critical to the achievement of the function of interest. It is typically preceded by first deeply understanding the biological mechanism of interest in its biological context. Once the biological mechanism is well understood, abstraction and articulation of the key variables in neutral or target domain-specific terminology is typically how the inspiration drawn from biology is made relevant and transferrable to a design or engineering application. Much of the research and databases of biological mechanisms developed to date provide insight into techniques for abstraction and transfer and are largely based on semantics and systematic language analysis. Various techniques are currently described in the literature, including functional decomposition [28,30-32], the function-means tree [33], concept-knowledge (C-K) modelling [34,35], checklist of key questions [36], the 'abstracting design principles' step of Biomimicry Thinking [10], causal relationship template [37], structure-behaviour-function (SBF) [38], what-why-how template [39], structured representations for biologically inspired design (SR.BID) or the Four Box Method [40], Design Analogy to Nature Engine (DANE) structured descriptions [41], the SAPPhIRE model of causality [42], as well as terminology supports such as analogical categories [5], the Engineering to Biology Thesaurus [43], and the Biomimicry Functional Taxonomy [10]. The strength of many of these approaches is in standardizing the process for isolating and identifying key variables of the biological mechanism and in some cases subsequently populating a rich, searchable database and/or to provide guidance on how to translate biological information to design and engineering language.

Fayemi [9] describes transferring, referred to as 'transposing', as the step "which enables designers to embody the outlined biological principles according to technical functionalities. Such transposition usually requires the available technological knowledge to act as a grid for interpreting the biological solution(s) and enabling its implementation into the technical world" [9]. The one to one mapping of attributes between a biological principle and a biomimicry design principle represents a particular challenge due to conceptual distance between domains. Because of this unique challenge, there is a need for more explicit direct strategies for performing analogical transfer [44].

Various studies have explored the issues that can challenge the successful abstraction and transfer of biomimicry design principles, including difficulty in isolating key elements [23], fixation on familiar biological phenomena [45], and the cognitive challenge of working with far source analogies [46]. There are two primary challenges this study addresses that are associated with the abstraction and transfer stages of the process. The first is the evaluation of the biomimicry design principle due to the multi-functionality of nature making it difficult to isolate aspects of biological models that contribute to the desired function [47], and because few tools exist to support the development and evaluation of biomimicry design principles and are derived from more general theories of analogy and design by analogy [40]. The second major challenge is collaboration across the domains of biology and design due to their differing vocabularies, professional norms and purposes of work, as a result, there is a growing need to determine what kinds of representations of biological systems facilitate understanding [48].

While abstraction and transfer tasks are particularly challenging, the associated challenges of evaluation and collaboration are common in most design processes and techniques have been established to aid designers as they navigate them. Specifically, prototyping is a well-studied and understood common practice in design that is part of the expanding influence of design thinking [49]. Design thinking is a generalized method of design that makes the benefits of a design-led approach to the development of strategic solutions more accessible to non-designers [50]. The purpose of prototyping in design thinking is to engage users, test usability, evaluate ideas and in this way serves as a form of research as the understanding of the problem and the solution develop in parallel [51]. However, 'prototype' is a wide-ranging concept that can have different meanings to different domains and is commonly used alongside similar terms, such as model and mock-up. While there are many possible definitions, the prototype as defined by Ulrich and Eppinger [15] as "an approximation of the 
product alone one or more dimensions of interest" is particularly useful for this research. The purpose of producing a prototype would be to embody a design hypothesis, then its functionality, and collect feedback prior to further development and production [15]. A prototype can take many forms and serve a variety of evaluation strategies, including functional, assembly, and appearance, among others [52]. By representing a design concept in physical form, a prototype can serve as a generator of ideas by making abstract ideas concrete and providing a focus for exploration and discussion [53]. Prototypes can also serve as "boundary objects" to span gaps between different competencies of those participating in the design process [13] and visualize the problem at the same level so that collaborators are working with a shared mental image [54].

There are many known instances of prototyping in biomimicry at a variety of scales, including architectural structures (Figure 2), materials (Figure 3), and furniture design (Figure 4) for example. Physical prototypes, in addition to digital simulations of prototypes analyzed through finite element analysis, have been described as helping to "explain the mechanics of the natural biological systems they mimic" [55] and to examine the complexity of biological references [56]. However, the opportunity to utilize prototyping in biomimicry to address abstraction and transfer as well as cross domain collaboration is not yet described in a way that provides general prototyping guidance to practitioners of biomimicry design as we have in other design and engineering domains.

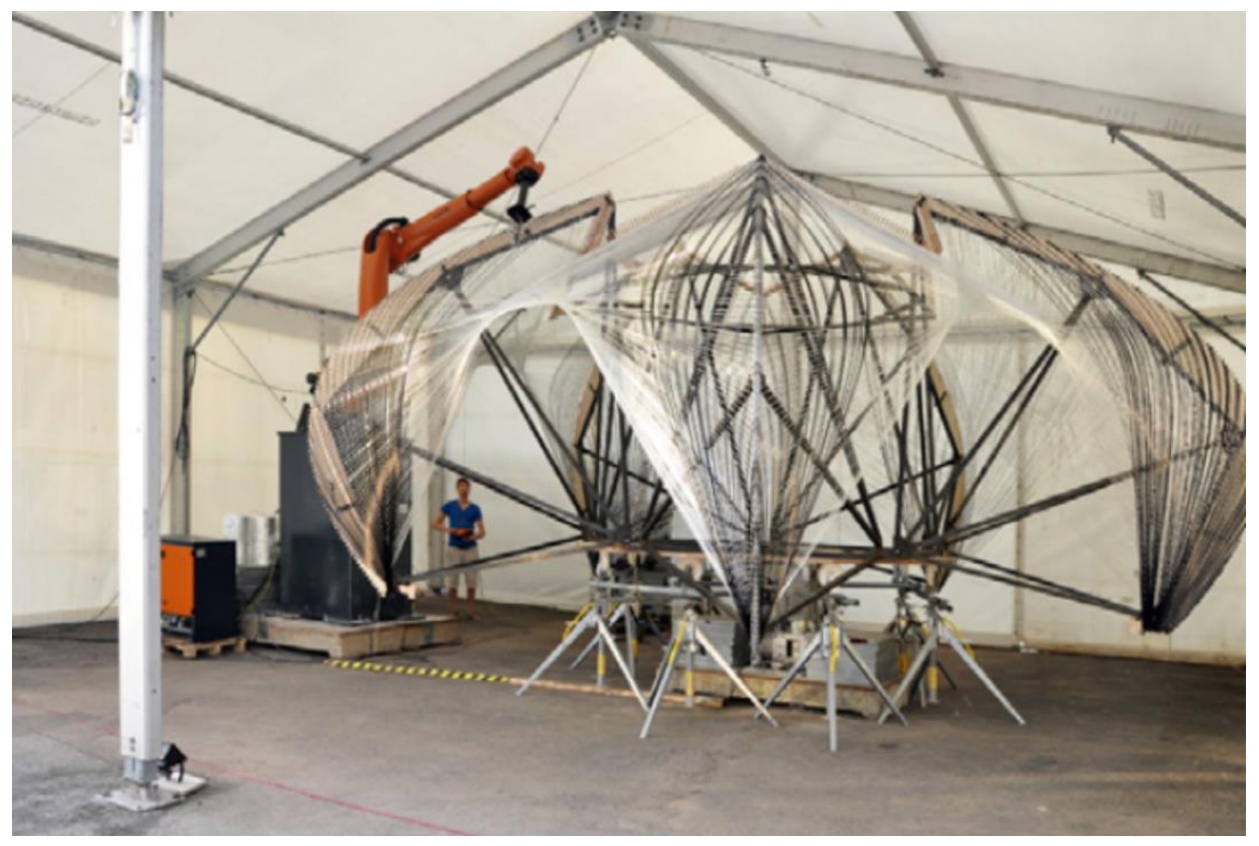

Figure 2. Architectural scale prototype of engineered structure demonstrating biomimicry design principle of lobster shell structure using fibrous composite materials assembled through robotic fabrication [57].
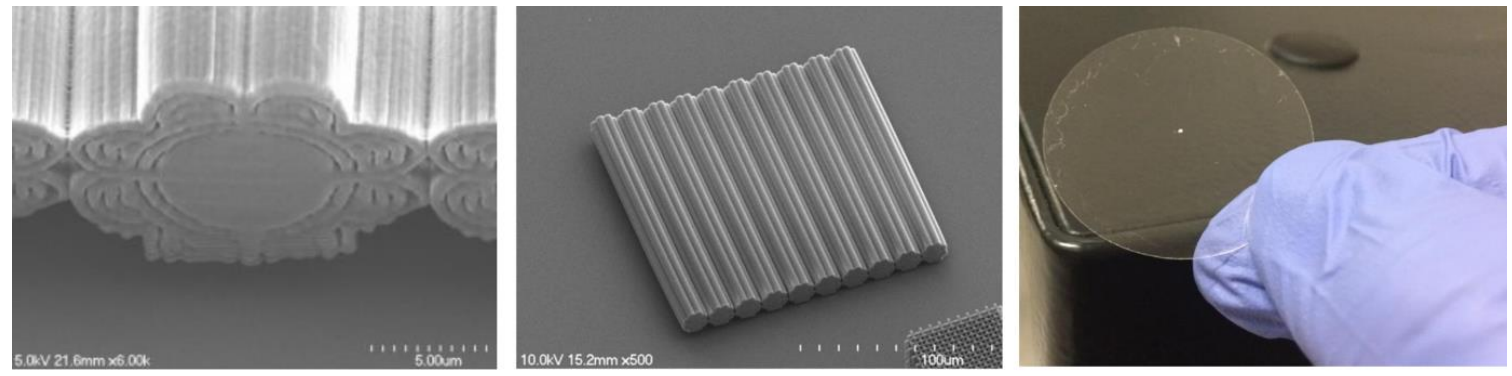

Figure 3. Series of images of a material prototype fabricated at $15 \mathrm{um}$ scale that demonstrates a biomimicry design principle of structural color based on observations of blue haired tarantula [58]. 

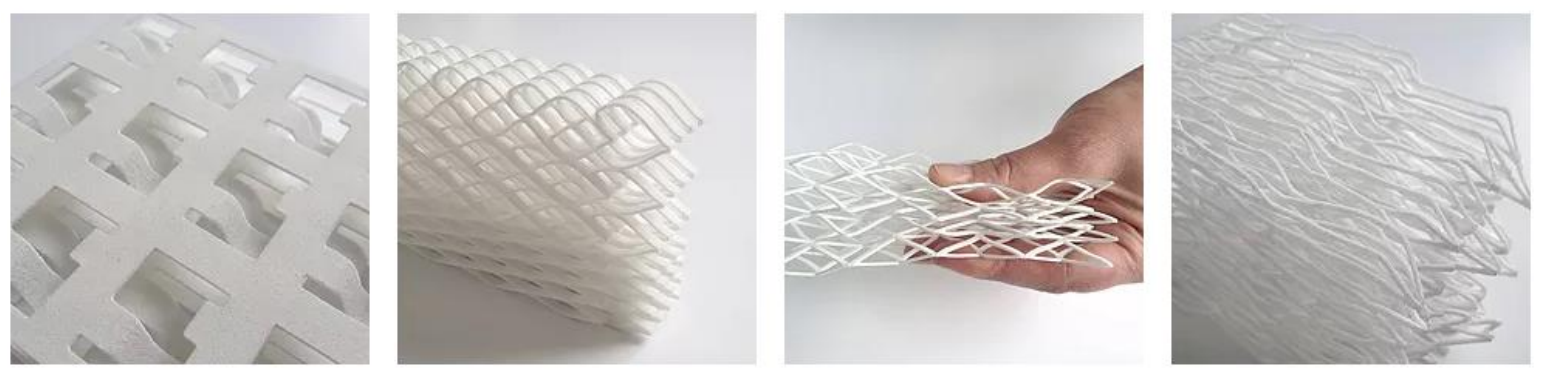

Figure 4. Series of prototypes demonstrating variations of possible structures inspired by radiolarians for application to soft seating [59].

Based on the known uses and benefits of prototypes in design practice, the aim of this study was to explore the popularity of prototypes among biomimicry practitioners currently and how abstraction, transfer and cross-domain collaboration between biologists and designers and engineers has been influenced by the utilization of prototyping. The goal was to describe current practices that provide general guidance on how to leverage the known benefits of prototyping to navigate the conceptual leap associated with working in a biomimicry design context.

\section{Materials and Methods}

The study followed a mixed methods sequential explanatory research design where initial quantitative data was further explored through qualitative data to help explain the findings [60]. Data from an initial online survey with 270 biomimicry practitioner respondents was collected over six weeks followed by ten semi-structured interviews with eleven biomimicry practitioners over an eight-week period. As per ethical protocols, all participants in both studies were volunteers and gave their informed consent prior to participating in the research.

\subsection{Sample}

For the online survey, an effort to be as inclusive as possible in the call for participants was made by reaching out to a wide variety of biomimicry networks, organizations, and leaders around the world. Using a criterion-based sampling procedure [61], 270 respondents that self-identified as having proficiency as a biomimicry practitioner at some level, including fundamental awareness, novice, intermediate, advanced, and expert (Figure 5), were permitted to proceed with the survey. Respondents were diverse in both their geographical dispersion across 44 countries as well as the range of employment sectors they represented. Among the 270 total respondents, 189 (or $70 \%$ ) were considered to have designerly and/or engineering skills sets based on their declared educational backgrounds and core competencies.

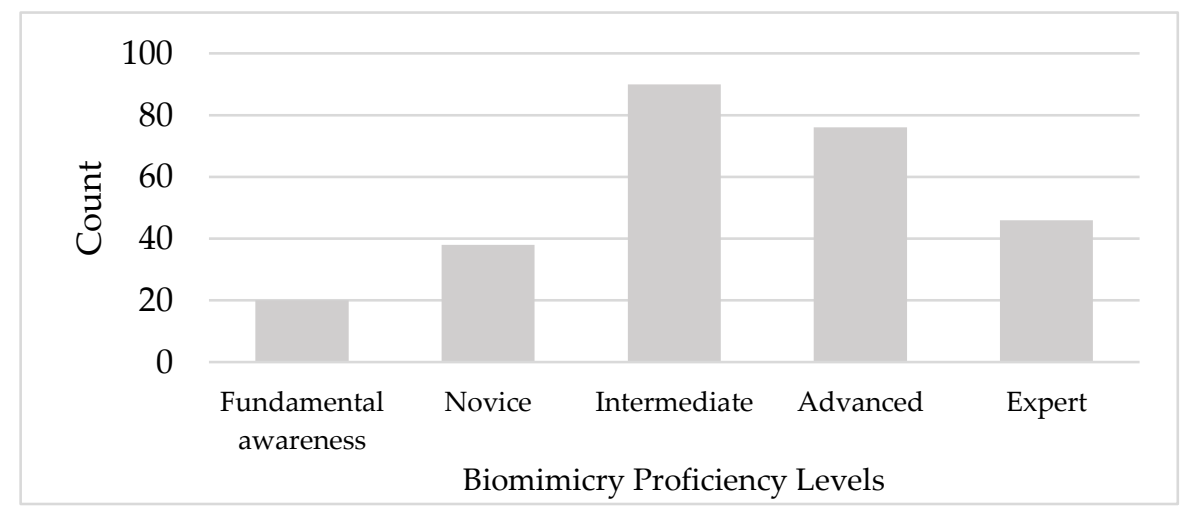

Figure 5. Biomimicry proficiency levels of online survey respondents. 
The sampling scheme for the subsequent interviews was purposive and based on a critical case approach [61], where individuals were chosen based the use of physical modelling in order to provide compelling insight into the role and impact of physical modelling on a biomimicry project. The eleven interview participants included those that have applied biomimicry to product, architectural, and material design and included both biologists and non-biologists and most drew from multiple project experiences in providing their responses to interview questions. The interview participants are summarized in Table 1.

Table 1. Summary of semi-structured interview participants.

\begin{tabular}{|c|c|c|c|c|}
\hline ID & Project Role & Application Areas & Project Types & Location \\
\hline P01 & Biologist & Product design & Architectural façade system & Europe \\
\hline P02 & Designer & Product design & Architectural façade system & Europe \\
\hline P03 & Biologist & $\begin{array}{l}\text { Material science } \\
\text { Product design }\end{array}$ & $\begin{array}{l}\text { Structural color material } \\
\text { Sports equipment }\end{array}$ & North America \\
\hline P04 & Designer & Product design & Urban agriculture system & Europe \\
\hline P05 & Urban agriculture expert & Product design & Urban agriculture system & North America \\
\hline P06 & Designer & Industrial design & Consumer packaging & Europe \\
\hline P07 & Biologist & Industrial design & Structural components & Europe \\
\hline P08 & Designer & Industrial design & Wine storage system & North America \\
\hline P09 & Designer & Product design & Soft seating & Europe \\
\hline P10 & Organic chemist & Material science & Soft seating & North America \\
\hline P11 & Engineer & Architecture & Structural systems & Europe \\
\hline
\end{tabular}

\subsection{Data Collection and Analysis}

The initial online survey collected data for: (1) popularity of physical modelling as a format for abstracting biomimicry design principles; and (2) challenges and techniques associated with abstracting and transferring biomimicry design principles. The survey questions were a combination of single or multiple response with the opportunity to provide free-text responses where appropriate. The quantitative data resulting from the survey was analysed using SPSS statistical software. Both descriptive and comparative statistics were run to meet the goals of the study. The comparative analysis used was the test of two proportions [62] (i.e., Chi-square test of homogeneity) that determined if a statistically significant correlation existed between those that did and did not report using physical models to represent their biomimicry design principles on a range of dependent variables, including difficulty scores for abstraction, transfer, and cross-domain collaboration, stage of project development achieved, and use of abstraction technique.

Follow-up interviews typically lasting 40-60 min collected richly descriptive narrative-style data on participants' experience with prototyping related to the abstraction and transfer of biomimicry design principles to a solution and were used to help explain the quantitative findings. Along with the interview transcripts, project images, published materials on their work (e.g., academic papers, articles, websites), and videos further describing the projects, such as TED talks and promotional videos, were analysed using NVivo, a qualitative data analysis software. The qualitative analysis included coding (keyword tags) and categorization (taxonomy) as well as meaning condensation [63] from the rich textual descriptions provided by the participants. Themes were inferred through patterns of similarity and then used to construct a tentative statement [64] about the impact that prototyping has in the context of the tasks of abstraction, transfer, and collaboration.

The study's outcomes were presented in a peer debriefing with 24 biomimicry practitioners, including faculty and graduate level students, associated with the Biomimicry Center at Arizona State University. Their verbal feedback has been incorporated; however, it was highly supportive overall with no major concerns expressed. 


\section{Results}

\subsection{Statistical Results on the Use of Prototyping among Biomimicry Practitioners}

Of the total 270 survey respondents, $57(21 \%)$ reported to have used physical models as a format for abstracting biomimicry design principles whereas illustration and text were the most commonly used formats being used by $74 \%$ of the respondents (Figure 6). Out of the 189 respondents that declared having designerly and/or engineering skills sets, the reported use of prototyping slightly increased to $23 \%$. There was an association between the use of physical models and the application areas of product design, industrial design, and materials science, however prototyping was reported as largely underutilized among practitioners in these employment sectors where it would normally be considered common practice (Figure 7).

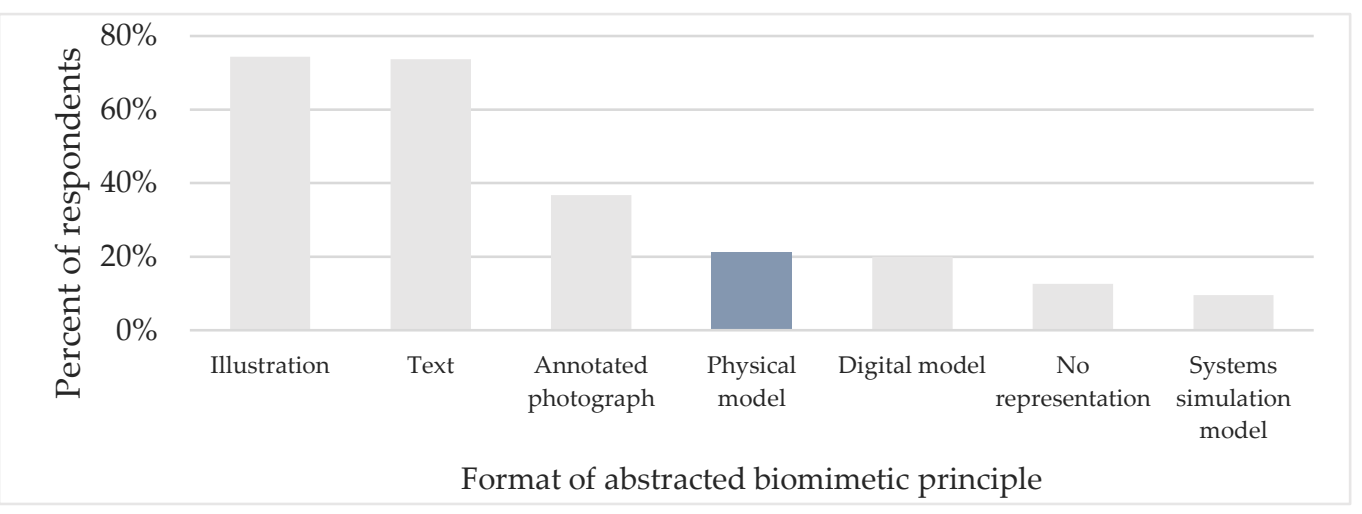

Figure 6. Formats used to represent abstracted biomimicry design principles as reported by surveyed practitioners.

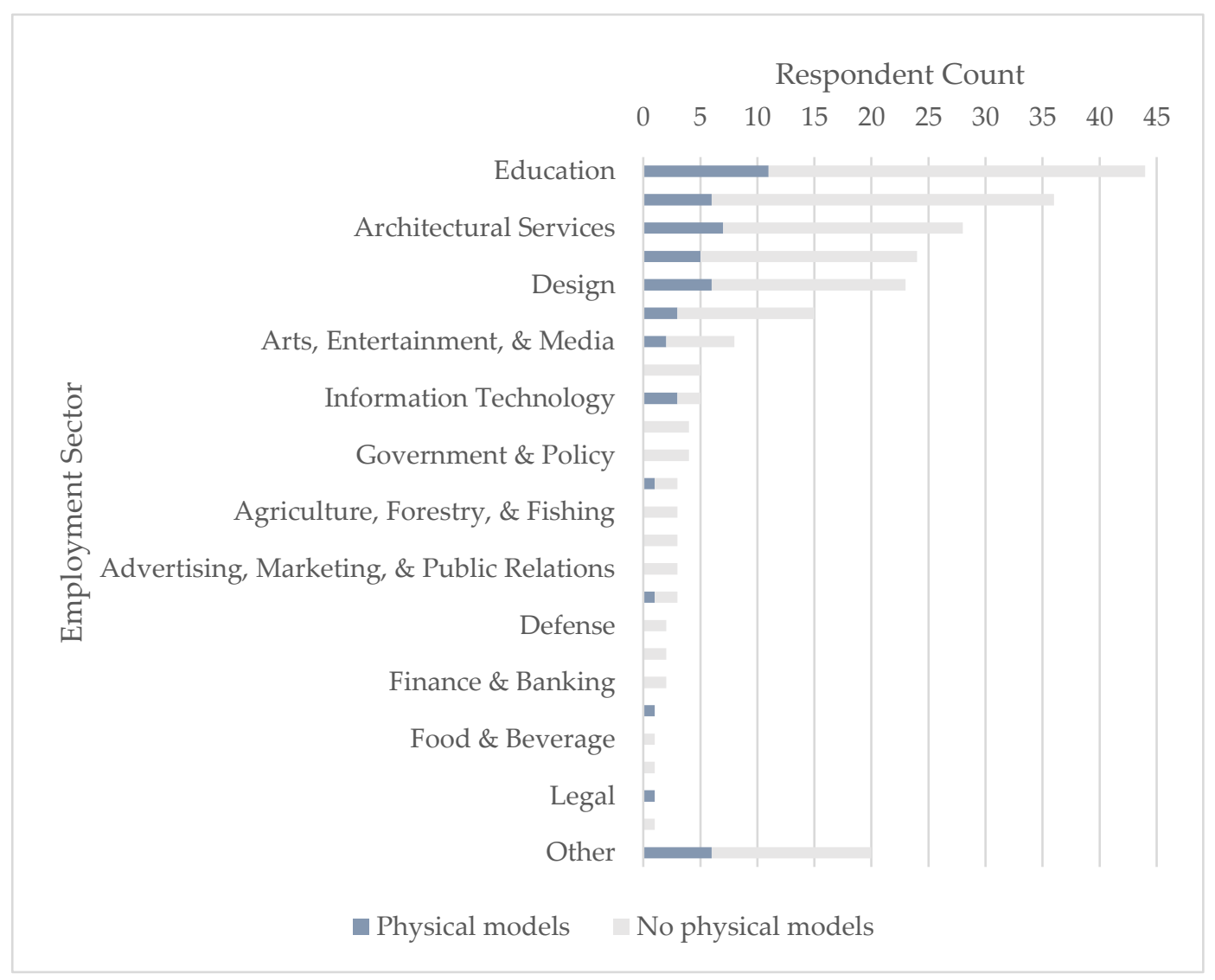

Figure 7. Use of physical models among survey respondents by employment sector. 
While the use of prototyping was not correlated with lower difficulty scores for abstraction, transfer, or cross-domain collaboration, a chi square test of homogeneity showed that it did have the strongest correlation of any format with projects reaching the implementation stage, $X^{2}(5)=34.959$, $p<0.001$, Cramer's V $=0.360$ [65].

Additionally, when asked which abstraction technique they used from a list developed from the literature review, including functional decomposition [28,30-32], the function-means tree [33], C-K modelling [34,35], checklist of key questions [36], the 'abstracting design principles' step of Biomimicry Thinking [10], causal relationship template [37], structure-behaviour-function [38], what-why-how template [39], SR.BID or the Four Box Method [40], DANE structured descriptions [41], the SAPPhIRE model of causality [42], and BioTRIZ [66], my own process of analysis and interpretation, none of the above, and other, $75 \%(n=43)$ of those that used physical models also reported that they use 'my own process', a statistically significant correlation, $\mathrm{X}^{2}(12)=8.876, p=0.003$, Cramer's V $=0.181$. Additional significant correlations between the use of physical models and 'checklist of key questions' and 'structure-function-behavior' as abstraction techniques were found, though with less prevalence. All responses to abstraction techniques used among those that used physical models are shown in Figure 8.

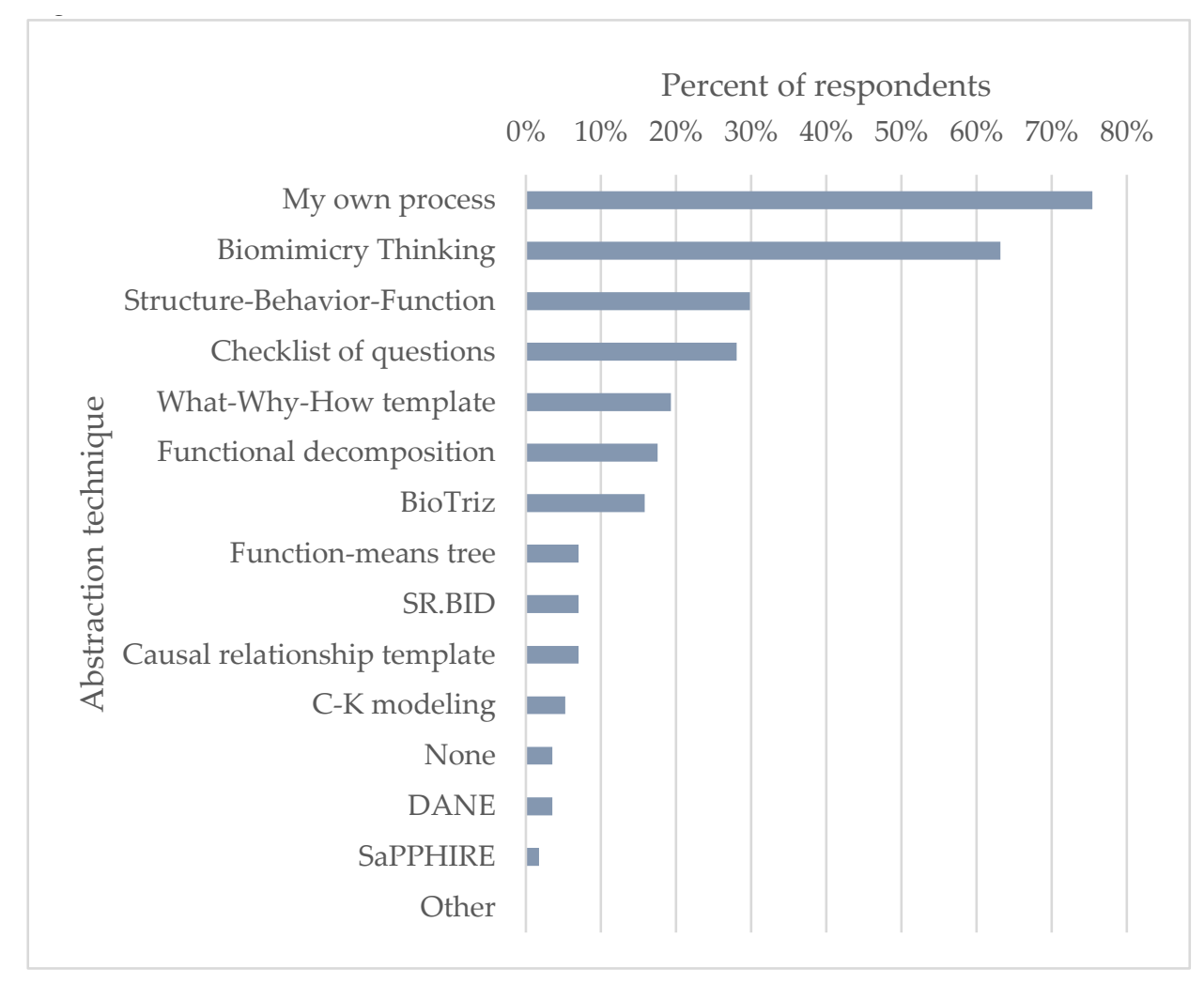

Figure 8. Use of abstraction techniques among survey respondents using physical models.

\subsection{Thematic Analysis of Interview Data}

To help explain the correlation between the use of prototypes and the respondents using their own process to abstract biomimicry design principles as reported in the survey, across case thematic summaries provide a synopsis of the interview participants' comments on the utility and impact of prototyping on their project related to (1) abstraction; (2) transfer; and (3) cross domain collaboration. Significant statements from the participants are included to further illustrate the nature of their experiences in their own words. 


\subsubsection{Utility of Prototyping for Abstraction \#1: form Finding and Approximation}

For eight participants, the role of prototyping on a biomimicry project was to initially approximate the forms and behaviors of their biological reference in a digital computer aided design (CAD) based environment. One participant commented on how their prototyping process starts: "Normally, I immediately go from (discovering a biological inspiration) to my computer and to my 3D program and try to create the structures" (P09). One participant commented on the importance of starting this approximation of the biomimetic principle early in the abstraction stage: "To get the functional principles, you don't need to make it like the actual product which would come out, but at least to prototype the principles" (P02).

\subsubsection{Utility of Prototyping for Abstraction \#2: Performance Testing}

Prototyping also appeared to serve as a hypothesis or assumption checking exercise where the biomimetic structures and behaviors were tested for their functional efficacy. One participant said: "The biologists, they investigated more on how this folding movement or motions are happening in the plant, their assumptions, which we then modelled and simulated to figure out if this assumption can be true or not" (P02). Four participants preferred to work digitally initially because the simulated validation of the working principles through finite element analysis allowed a more rigorous analysis of external loading and reduction of stress concentrations as well as early detection of misinterpretations or oversimplification of the biological principle. The ability to conduct performance evaluation was a common pattern among participant's motivation for prototyping during the abstraction phase. One participant noted that the digital prototype's validation of performance can fail even if you have interpreted the biological mechanism correctly but transferred it to the design using the wrong material: " ... It can also be that the interpretation of the natural model might be correct but it's being applied in a wrong way to, in this case for example, to a bottle, or the interpretation that I have from the natural structural system might be fully correct, but I might apply it to a bottle whose material doesn't make sense to apply that structural system" (P06).

\subsubsection{Utility of Prototyping for Abstraction \#3: Cataloguing Biomimicry Design Principles}

For five participants, the modelling and prototyping allowed elements of the biomimicry design principle to be isolated, tested, and reconfigured into a range of variations with varying performance results. Subsequently, as successful working principles are identified, they could be added to a digital catalogue of validated biomimicry design principles specific to their typical design domain. One participant said: "We really don't try to look at one biological role model and then transfer this into a technical application, but we really try to abstract the principles and then combining them all to create even, let's say, a working catalogue" (P02).

\subsubsection{Utility of Prototyping for Transfer \#1: Establishing a Prototyping Principle}

All participants referred to the importance of developing a 'prototyping principle' or a 'materialization principle' as part of both abstracting, transferring, and, in a couple cases, even selecting biological principles that seemed the most compatible with their prototyping principles. These were indigenous terms used explicitly by three interview participants referring to the consideration and selection of appropriate materials, fabrication methods, and scale that would be used to actualize the functional principle. Throughout the interviews, participants described in various ways that the functional principle had to be interpreted in the context of viable materials and fabrication methods in order to be transferrable. One participant commented: "The abstraction process is super important. How to abstract, let's say, the functional principal, and also materialization principles, how they are not necessarily the same. [On our project] the materialization principle is very closely related to the geometrical [requirements] that come from a plant; however, the plant is not at all materialized as we did it" (P02). Eight participants described a common experience of developing their biomimicry design 
principle through the opportunities and limits presented by the materials and fabrication methods that they worked with. As a result, the ability to prototype the design principle actually guided the abstraction and interpretation of the principle itself. For example, one participant commented on how limitations with additive manufacturing effected their process: "If we can make exactly the [biological] structure it will work the best, but just based on all kinds of (technical) limitations we need to take what we learn from that principle and make what is doable right now. So, we simplified the structure. Still, it can work better than just the material itself" (P03). Another participant commented on the difference between how nature materializes compared to their tendency to work with steel, aluminum, and fiber reinforced plastics as viable materialization options: "What is extremely interesting is also the material. The diatoms are made of glass or something like glass overall, silica, but it is very strong" (P07). Another participant said: "Of course, I want to use biological materials, but there are still no biological materials to use in selective laser sintering (SLS) printing" (P09).

Six participants commented on how advanced technologies to fabricate biologically inspired designs are cost-prohibitive and a limiting factor for moving forward with design development. One participant said: "A lot of biomimics just assume, and we assumed, that you could just [3D print] in a way that makes sense biologically. It's super expensive to do that. And it also isn't necessarily functional. I mean, 3D printing all the time, it's good for prototyping, but it's not necessarily for final scale. It just gives you an impression of how things will work. It's not exact" (P05). Six participants noted the limits of additive manufacturing in producing functional, scaled forms that emulate biological morphologies. "There are other factors you have to consider such as restrictions of the production methods. Even in additive manufacturing, you cannot do everything. You have to comply with certain restrictions and then you produce it. It is still difficult to create these crazy intriguing forms which regularly occur in nature" (P11). Abstracting the biological principle in the context of the prototyping principle was a creative and intuitive challenge for participants and relied heavily on their own skills and access to resources in order to effectively problem solve. One participant said: "For both (of my biomimicry design principles), one way or another we needed to make some adjustments and sacrifices. We cannot make $100 \%$ the replica of each structure" (P03).

\subsubsection{Utility of Prototyping for Transfer \#2: Dealing with Trade-Offs}

Prototyping was often described as confronting the participants with difficult decisions that implied making tradeoffs between issues such as practicality and sustainability or innovation and cost effectiveness, for example. As a solution for dealing with the challenges of finding a good prototyping principle for their projects, eight participants opted for readily available materials that come in workable dimensions and abstracted the design principle within those constraints. One participant noted that while fixing these parameters limited the range of possibilities, it also focused the problems that needed to be addressed: "Having or fixing certain parameters at the beginning of the design process, is definitely a plus on the long run. It tends to narrow down the research and gives a very clear idea of what to do in that design process" (P11). While at times representing a tradeoff for sustainability issues, fixing the prototyping principle offered pragmatic advantages that were critical to moving their projects forward. One participant explained: "At the end, you could do almost everything, I would say, but you also need to take into account that somebody needs to produce it and someone needs to pay it" (P02). The choice of materials and fabrication methods was often cited by participants as the point in which sustainability concerns can arise. One participant speculated that the conflict between the sustainability ethics of biomimicry and the limitations of existing materials and fabrication methods may be inhibiting more practitioners from prototyping: "I think the reason a lot of these designers are not prototyping is that they know that their concepts are not quite feasible in a larger manufacturing sense. So it's like well let's just sketch it out, we'll storyboard it out, we'll do all the drawings that we can, but we know that we can't be making our product as of today the way that that nature would really intend because of the manufacturing technology is not there yet" (P08). 


\subsubsection{Utility of Prototyping for Transfer \#3: Proof of Transferrable Biomimicry Design Principle}

In seven cases, a participant felt a physical prototype was necessary as proof that the biomimicry design principle is possible and works outside of digital simulation. One participant commented: "I know for me to demonstrate that (the biomimicry design principle), simulation is not enough. You cannot use simulation to really convince people, because no one thinks that is doable. So, I need to do a physical prototype" (P03). In a couple of other cases, the participants preferred to do their performance testing physically as direct evidence of whether all the desired properties are being achieved: One participant commented: “... As soon as possible I go to the 3D printer and see what's coming out of it because in the computer I cannot see if it works or how I think it should be to have the best flexibility" (P09). One participant noted that not yet being able to produce a physical prototype from a digital simulation serves an indication that the design principle has not yet been well understood enough to be transferrable: "When you can't get the ideas out of your computer with simple hand models, it means that something is missing or you need to do this jump from the digital to the physical in small scale until you're able to master the complexity" (P11).

\subsubsection{The Effect of Prototypes on Cross-Domain Collaboration \#1: Visualizing a Biomimicry Design Hypothesis}

Prototypes and other visual aids were noted by five participants for their usefulness in communicating needs and concerns on their projects. One participant reflected: "(Prototypes) are definitely one tool that can have the biologist talk to the engineer more easily because there's a tangible object." (P03) Four participants noted that biologists are not trained in design issues and often have a narrow focus in their biological expertise. Having a series of prototypes allowed one participant to let the biologists feel and observe the concept and see the design concerns and goals that helped the biologists understand what information would be useful. The participant said: "I always bring my 3D models and my experiments to [the biologists] and say 'Here you can feel that it reacts like this, but I am expecting it to do this, or I was expecting it should do this or this', and then we try to figure it out together-me from my engineering point of view or my design point of view, and them from their biology point of view. And then we see if we can come up with why it reacts like that" (P09).

From the other perspective, one participant with a biology background commented on how tangible prototypes of what the designer was interested in helped them in their role: "I liked it very much when the designers could show me one of the universal movement principles, like, for example, the curve line folding principle, because then you find yourself checking all the organisms you know of if they also employ this rather common design or motion principle" (P01). Another participant with a biology background commented on how prototyping also helped their engineering team visualize biological phenomena and better analyse its microscopic structure: "We analyse (microscopic organisms) with laser confocal microscopy where you get a quiet good resolution and then you have this item in much bigger size by a factor of, for instance, 10,000 or so, on your table and it's really beautiful and you understand it differently ... When we printed [the physical model], its depth and dimension become more apparent than in the scanning electron microscope" (P07).

\subsubsection{The Effect of Prototypes on Cross-Domain Collaboration \#2: Optimizing Collaboratively}

For six participants, having the physical prototype facilitated mutual understanding between the design and biology experts of the challenges, opportunities, and limitations of applying principles derived from biology to a real-world solution while at the same time attempting to maintain the sustainability implications of a biologically inspired design approach. One participant commented: "There's this iterative cycle between checking in with the biologists and the (Life's Principles) and to say how would nature do this then going off and solving for materiality issues, scaling issues, user needs issues, and then working on that and then come back and say, "Okay, how do we optimize this again from the biology," and going back and forth" (P05). Another participant commented on how the performance of the prototypes drove the iterative biological research cycle: "Inevitably when you're 
trying to go from brand new novel idea to something tangible, there are many obstacles along the way. You may plan out and say, 'We'll do this, and this will lead to that.' But there's all sorts of technical problems you find when you actually try to put it into operation. And so, the team as a whole would try to solve them each time we bumped into them and my role was to sort of go back to the biology and pull from nature to find a solution" (P10).

\subsubsection{The Effect of Prototypes on Cross-Domain Collaboration \#3: Self-Checking}

Not all participants worked closely with biologists as they abstracted and transferred their biomimicry design principles preferring instead to explore and synthesize biological information themselves. One participant shared: "Because I work here and I know very well the specifics of what we need to solve and what we need to, it's much easier for me to look for natural models and study them than to ask a biologist to do that for us. We tried that in the past but didn't work so well ... One thing that usually happens is that, the way [biologists] filter the information, they might be putting aside information that is actually important for us to help us understand the organism to the core. And so, I prefer to receive the rough data that might not be so appealing to read but I try to. It takes time, of course" (P06). For the three participants that shared this perspective, the prototyping appears to serve as a self-checking tactic for both the understanding of the biology, developing a prototyping principle, and testing the efficacy of the synthesis of the two. One participant commented that while more time consuming, it is still the most effective process for them: "Not the most efficient process, but it really works for me. Also, to understand as a designer because I'm not a biologist and engineer, so it is an intuitive process and trial and error all the time" (P09).

\section{Discussion}

While the results did not indicate that prototyping could be correlated with reduced difficulty in the tasks of abstraction, transfer, and cross domain collaboration, several themes on its unique utility in aiding the biomimicry process have been described. Prototyping had a significant correlation with projects reaching the implementation stage, however this finding is certainly influenced by factors beyond prototyping not addressed in this study. Nonetheless, it suggests that prototyping is a contributing factor to improve the odds of reaching project implementation. This may be due to its ability to make abstract ideas concrete and embody and evaluate a design hypothesis as was described in the interviews as well as in the research of Ulrich and Eppinger on the purpose of prototyping [15].

The association between the use of physical models and the application areas of product design, industrial design, and materials science found through the survey was reinforced in the interviews with the addition of architecture. Within the limits of this survey, evidence suggests that biomimicry projects of a physical, three-dimensional nature are, perhaps unsurprisingly, more likely to use prototypes. However, within these generalised sectors the motive and focus for prototyping can range greatly in fidelity and evaluation purpose, including material construction, mechanical functionality and fabrication. Furthermore, 2D prototyping, schematics, walkthroughs and digital models offer another view on prototyping biomimetic principles as both prequals to 3D and within other domains such as process, services and systems design.

Interestingly, physical modeling appears to be an underutilized technique among practitioners in sectors and with skill sets where it is normally considered common practice, such as design and engineering. This might partially be explained by the increased use of digital models, as was largely the case in the interview participants where digital models often preceded physical models. It was observed that nearly all interview participants utilized digital modeling alongside their physical model(s) with only one instance of hand-built prototypes.

\subsection{Performance-Based Abstraction of Biomimicry Design Principles through Prototyping}

Based on the interview findings, we have outlined a 'performance-based abstraction' process (Figure 9) that serves as insight into the survey response by $75 \%$ of the prototyping respondents that 
reported using 'my own process' to abstract biomimicry design principles. It is comprised of four key activities:

- Approximation: A 'rough draft' model of forms and structures, frequently in digital format, that closely approximates the morphology and behavior(s) of the biological reference.

- The Prototyping Principle: The selection of existing materials and fabrication methods that would serve as proxies to those used by the biological reference. In four cases, the prototyping principle influenced the participant's choice of biological reference(s) and actually occurred prior to the approximation stage.

- Synthesis and Testing: The synthesis of the approximated model and the prototyping principle into a biomimicry design principle, testing the efficacy of the applied prototyping principle and the interpretation of the biological reference either physically, in a simulated environment, or both, and optimizing until expected functionality is achieved and project performance requirements are met.

- Validation: A decision making point where either the biomimicry design principle is validated and can progress forward into a design solution and potentially be stored in a catalogue of validated design principles, or whether there are more questions about whether the biological reference has been understood accurately and/or the choice in materials and fabrication method have been appropriately applied leading to further investigation.

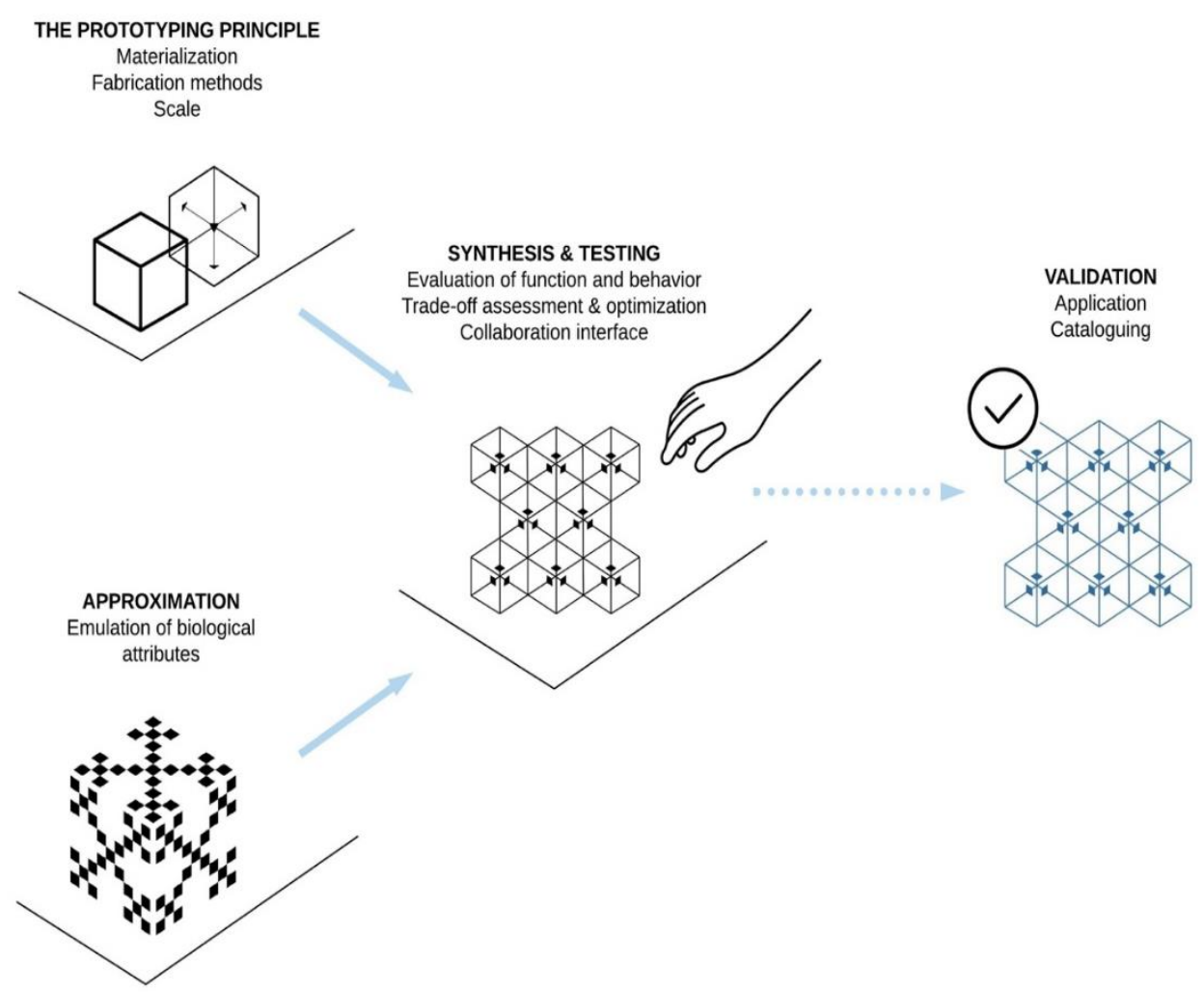

Figure 9. Key activities for the 'performance-based abstraction' of biomimicry design principles.

A key difference with this approach compared to currently described techniques of abstracting biomimicry design principles is the relationship between the distinct activities. While biomimicry is widely regarded as a highly iterative process, attempts to describe its process in a straightforward manner as a somewhat linear sequence of stages runs the risk of suggesting that a biomimicry design principle is articulated and then materialized [9] whereas the performance-based abstraction process proposes that a biomimicry design principle can be interpreted through its materialization and the limits and opportunities presented by fabrication methods at scale. In fact, fixing or limiting the 
elements of the prototyping principle may provide an advantage to more efficiently develop design and engineering solutions because of the focusing effect it has on perceived problems and solutions.

Another key difference is that the performance-based abstraction process is largely non-semantic relying on form finding and collaborative evaluation over language analysis. While the majority of the participants processes appear rigorous, it is conceivable that a downside to this form finding approach could lead to what prior research has found to be a superficial level of understanding of the biological mechanism based only on what is directly observable [5]. However, when coupled with performance testing, this risk appears to be mitigated as achieving the desired functional efficacy remains the design objective and the outcomes can become more predictable.

The analogical reasoning experiences described by participants appeared similar to that of the known structure-behavior-function (SBF) models where the biological reference is systematically analyzed by mapping the behaviors driving the desired functional effects to the structural components that make the behavior possible [67]. The interview results indicated that it was the structural elements of the biology that seemed to trigger the abstraction process in a tightly integrated fashion with the prototyping principle. In this way, the semantic bridge of function often described in biomimicry may be a means for searching for relevant biological references, but with the performance-based abstraction approach it is the performance of the structures within existing materials and fabrication methods that drive the abstraction and transfer and where functional performance of the prototype serves as the evaluation criteria.

\subsection{Prototypes of Biomimicry Design Principles as Boundary Objects between the Distant Domains of Biology and Design}

Utilizing prototypes on a biomimicry project through the proposed performance-based abstraction approach may provide a unique collaboration interface that surfaces key issues, such as biological mechanism details, sustainability, and material or fabrication limits, for both biologists and designers where ongoing challenges of differing language, concepts, and purposes persist as is typical in design by analogy drawing from far sources [68]. In this way, it appears to serve as a useful boundary object between experts from biology and design or engineering domains in the same way that prototypes are known to engage key stakeholders in the understanding of both the problem and the solution of a challenge [13]. In the case of biomimicry, the prototype as a boundary object between biology and design helps the biologists understand the design opportunities and limits and trigger ideas for relevant biological models and for the designer or engineers appears to help improve the integrity of their understanding of how the biological mechanism works and where missed opportunities may reside.

\subsection{Limitations}

While this study yielded new insights into the use of prototypes on some form-based biomimicry projects, several limitations exist that should be considered when interpreting the findings. The study included participants working in multiple fields with various vocabularies and norms of practice in order to maximize diversity, however this added complexity to the coding and thematic analysis that proved challenging in categorically organizing the data. Another limitation is that the interviews captured participant reflection, but no direct observations of prototyping in action and how it affected abstraction, transfer, and collaboration were made.

\subsection{Opportunities for Further Research}

To address the limitations of this study, further work in this area might choose to expand on the results reported here by conducting further qualitative inquiry, especially direct observation and/or participatory research involving biomimicry practitioners using the performance-based abstraction approach. This further work could also provide photo documentation of participant processes to provide visual examples of the activities and outcomes of each phase. Larger and more diverse 
participant samples segmented according to their field, such as architecture, product design, materials science, and engineering, might be able to describe how and whether the performance-based abstraction approach aids the specific materials, fabrication, scale, and sustainability concerns practitioners are encountering in their respective fields. While the survey captured data on respondent's use of various abstraction techniques, it did not assess their level of familiarity with each. Further work could investigate the biomimicry practitioner community's familiarity with these abstraction techniques in order to explore the rationale behind the varying percentages of use reported in this study.

It was also suggested that the analogical reasoning described by participants appeared similar to that of the structure-behavior-function (SBF) model for analogical transfer. Further research could investigate how and whether the existing knowledge on SBF methods could be used to guide a more predictable biomimicry prototyping strategy.

\section{Conclusions}

Designers and engineers are increasingly drawing analogous solutions from biological models through the biomimicry design process. However, the conceptual distance between biology and design and engineering intensifies the challenge of abstracting and transferring analogical solutions. Evaluating biomimetic design principles and collaborating across the biology and design knowledge domains represent difficulties for practitioners that increase time and effort required. Prototyping is a common design practice that is known to support evaluation and collaboration and this study has described its use specifically in a biomimicry design context. Based on survey and interview data capturing the current practices of biomimicry practitioners, this study has outlined a performance-based abstraction approach that offers guidance to practitioners on how to use prototyping, both digital and physical, starting in the abstraction stages rather than waiting for the application and concept development stages more typically associated with the application of design skills. Performance-based abstraction is described as providing a pragmatic approach to the synthesis and testing of conceptually distant ideas derived from biology through the materials, fabrication methods, and scale of a design or engineering project. It allows not only the evaluation of the variables at play but also in serving as a boundary object between experts in design and biology.

Because of its ability to surface key biomimicry design and collaboration issues as well as its correlation with projects reaching implementation, prototyping appears to be an important tool for practitioners, particularly for those working in three-dimensional design, and should be a promoted skill within trainings.

Author Contributions: Conceptualization, E.R. and J.M.; Methodology, E.R. and J.M.; Software, E.R.; Validation, E.R.; Formal Analysis, E.R.; Investigation, E.R.; Resources, E.R. and J.M.; Data Curation, E.R.; Writing-Original Draft Preparation, E.R.; Writing-Review \& Editing, J.M.; Visualization, E.R.; Supervision, J.M.; Project Administration, E.R.

Funding: This research received no external funding.

Conflicts of Interest: The authors declare no conflict of interest.

\section{References}

1. Bioinspiration: An Economic Progress Report. Available online: http://www.magnefico.com/fileadmin/user upload/Dokumente/PLNU_Bioinspiration_Da_Vinci_Index_A_Progress_Report_November_2013_Final. pdf (accessed on 14 July 2019).

2. Jacobs, S.R.; Nichol, E.C.; Helms, M.E. "Where Are We Now and Where Are We Going?" The BioM Innovation Database. J. Mech. Des. 2014, 136, 111101. [CrossRef]

3. Rovalo, E.; McCardle, J.R. Growing the practice of biomimicry: Opportunities for mission-based organisations based on a global survey of practitioners. J. Technol. Anal. Strateg. Manag. 2019. [CrossRef]

4. Appio, F.P.; Achiche, S.; Martini, A.; Beaudry, C. On designers' use of biomimicry tools during the new product development process: an empirical investigation. Technol. Anal. Strateg. Manag. 2017, 29, 775-789. [CrossRef] 
5. Nagel, J.; Schmidt, L.; Born, W. Establishing Analogy Categories for Bio-Inspired Design. Designs $2018,2$. [CrossRef]

6. Martín-Gómez, C.; Zuazua-Ros, A.; Bermejo-Busto, J.; Baquero, E.; Miranda, R.; Sanz, C. Potential strategies offered by animals to implement in buildings' energy performance: Theory and practice. Front. Archit. Res. 2019, 8, 17-31. [CrossRef]

7. Hsiung, B.K.; Siddique, R.H.; Jiang, L.; Liu, Y.; Lu, Y.; Shawkey, M.D.; Blackledge, T.A. Tarantula-Inspired Noniridescent Photonics with Long-Range Order. Adv. Opt. Mater. 2017, 5, 1-6. [CrossRef]

8. Snell-Rood, E. Bring biologists into biomimetics. Nature 2016, 529, 277-278. [CrossRef]

9. Fayemi, P.E.; Waniek, K.; Zollfrank, C.; Maranzana, N.; Aoussat, A.; Speck, T. Biomimetics: Process, tools and practice. Bioinspir. Biomim. 2017, 12, 0110022. [CrossRef]

10. Baumeister, D.; Tocke, R.; Dwyer, J.; Ritter, S.; Benyus, J. Biomimicry Resource Handbook: A Seedbank of Best Practices; Biomimicry 3.8: Missoula, MT, USA, 2012.

11. Badarnah, L.; Kadri, U. A methodology for the generation of biomimetic design concepts. Archit. Sci. Rev. 2015, 58, 120-133. [CrossRef]

12. Chan, J.; Dow, S.P.; Schunn, C.D. Do the best design ideas (really) come from conceptually distant sources of inspiration? Des. Stud. 2014, 36, 31-58. [CrossRef]

13. Brandt, E. How Tangible Mock-Ups Support Design Collaboration. Knowl. Technol. Policy 2007, $20,179-192$. [CrossRef]

14. Gero, J.S. Design Prototypes: A Knowledge Representation Schema for Design. AI Mag. 1990. [CrossRef]

15. Ulrich, K.; Eppinger, S. Product Design and Development, 6th ed.; McGraw Hill Education: New York, NY, USA, 2016.

16. Benyus, J.M. Biomimicry: Innovation Inspired by Nature; Harper Perrenial: New York, NY, USA, 1997; ISBN 0688160999.

17. Benyus, J.M. A Biomimicry Primer. In Biomimicry Resource Handbook: A Seedbank of Best Practices; Biomimicry 3.8: Missoula, MT, USA, 2013; pp. 7-19.

18. Kennedy, E.; Fecheyr-Lippens, D.; Hsiung, B.-K.; Niewiarowski, P.H.; Kolodziej, M. Biomimicry: A Path to Sustainable Innovation. Des. Issues 2015, 31. [CrossRef]

19. Komiyama, H.; Takeuchi, K. Sustainability science: building a new discipline. Sustain. Sci. 2006, 1, 1-6. [CrossRef]

20. Lepora, N.F.; Verschure, P.; Prescott, T. The state of the art in biomimetics. Bioinspir. Biomim. 2013, 8, 10-12. [CrossRef]

21. Speck, T.; Speck, O. Process sequences in biomimetic research. WIT Trans. Ecol. Environ. 2008, 114, 3-11.

22. Gebeshuber, I.C.; Drack, M. An attempt to reveal synergies between biology and mechanical engineering. Proc. Inst. Mech. Eng. Part C J. Mech. Eng. Sci. 2008, 222, 1281-1287. [CrossRef]

23. Helms, M.; Vattam, S.S.; Goel, A.K. Biologically inspired design: process and products. Des. Stud. 2009, 30, 606-622. [CrossRef]

24. Vattam, S.; Helms, M.; Goel, A.K. Biologically-Inspired Innovation in Engineering Design: A Cognitive Study; Graphics, Visualization and Usability Center, Georgia Institute of Technology: Atlanta, GA, USA, 2007.

25. Vattam, S.S.; Helms, M.E.; Goel, A.K. A content account of creative analogies in biologically inspired design. Artif. Intell. Eng. Des. Anal. Manuf. 2010, 24, 467-481. [CrossRef]

26. Holyoak, K.J.; Thagard, P. Mental Leaps: Analogy in Creative Thought. Am. Polit. Sci. Rev. 1995, 89, 745.

27. Wanieck, K.; Fayemi, P.-E.; Maranzana, N.; Zollfrank, C.; Jacobs, S. Biomimetics and its tools. Bioinspired Biomim. Nanobiomater. 2017, 6, 53-66. [CrossRef]

28. McInerney, S.; Khakipoor, B.; Garner, A.; Houette, T.; Unsworth, C.; Rupp, A.; Weiner, N.; Vincent, J.; Nagel, J.; Niewiarowski, P. E2BMO: Facilitating User Interaction with a BioMimetic Ontology via Semantic Translation and Interface Design. Designs 2018, 2, 53. [CrossRef]

29. Mead, T.; Jeanrenaud, S. The elephant in the room: biomimetics and sustainability? Bioinspired Biomim. Nanobiomater. 2017, 6, 113-121. [CrossRef]

30. Tinsley, A.; Midha, P.; Nagel, R.; McAdams, D. Exploring the Use of Functional Models As a Foundation for Biomimetic Conceptual Design. In Proceedings of the ASME 2007 International Design Engineering Technical Conferences and Computers and Information in Engineering Conference, Las Vegas, NV, USA, 4-7 September 2007; pp. 1-15. 
31. Nagel, J.K.S.; Nagel, R.L.; Stone, R.B. Abstracting biology for engineering design. Int. J. Des. Eng. 2011,4 , 23. [CrossRef]

32. Nagel, J.K.S.; Stone, R.B.; McAdams, D.A. Function-Based Biologically Inspired Design. In Biologically Inspired Design; Springer: London, UK, 2014; pp. 95-125.

33. Ernst Eder, W. Engineering design science and theory of technical systems: Legacy of Vladimir Hubka. J. Eng. Des. 2011, 22, 361-385. [CrossRef]

34. Salgueiredo, C.F.; Hatchuel, A. Beyond analogy: A model of bioinspiration for creative design. Artif. Intell. Eng. Des. Anal. Manuf. AIEDAM 2016, 30, 159-170. [CrossRef]

35. Nagel, J.K.; Pittman, P.; Pidaparti, R.; Rose, C.; Beverly, C. Teaching bioinspired design using C-K theory. Bioinspired Biomim. Nanobiomater. 2016, 6, 77-86. [CrossRef]

36. Vakili, V.; Shu, L.H. Towards biomimetic concept generation. In Proceedings of the ASME 2001 Design Engineering Technical Conferences, Pittsburgh, PA, USA, 9-12 September 2001.

37. Cheong, H.; Shu, L.H. Supporting Creative Concept Generation by Engineering Students with Biomimetic Design. Proc. Can. Eng. Educ. Assoc. 2010. [CrossRef]

38. Goel, A.K.; Rugaber, S.; Vattam, S. Structure, behavior, and function of complex systems: The structure, behavior, and function modeling language. Artif. Intell. Eng. Des. Anal. Manuf. 2009, 23, 23-35. [CrossRef]

39. Yen, J.; Helms, M.; Tovey, C.; Goel, A.; Weissburg, M. Adaptive Evolution of Teaching Practices in Biologically Inspired Design. In Biologically Inspired Design; Springer: London, UK, 2014; pp. 245-267.

40. Helms, M.; Goel, A.; Michael Helms, A.K.G. The Four-Box Method: Problem Formulation and Analogy Evaluation in Biologically Inspired Design. J. Mech. Des. 2014, 136, 111106. [CrossRef]

41. Goel, A.K.; Vattam, S.; Wiltgen, B.; Helms, M. Cognitive, collaborative, conceptual and creative-Four characteristics of the next generation of knowledge-based CAD systems: A study in biologically inspired design. CAD Comput. Aided Des. 2012, 44, 879-900. [CrossRef]

42. Chakrabarti, A.; Sarkar, P.; Leelavathamma, B.; Nataraju, B.S. A functional representation for aiding biomimetic and artificial inspiration of new ideas. Artif. Intell. Eng. Des. Anal. Manuf. 2005, 19, 113-132. [CrossRef]

43. Nagel, J.K.S.; Stone, R.B.; Mcadams, D.A. An Engineering-To-Biology Thesaurus for Engineering Design. In Proceedings of the ASME 2010 International Design Engineering Technical Conferences and Computers and Information in Engineering Conference, Montreal, QC, Canada, 15-18 August 2010; pp. 1-11.

44. Chiu, I.; Shu, L.H. Biomimetic design through natural language analysis to facilitate cross-domain information retrieval. Artif. Intell. Eng. Des. Anal. Manuf. 2007, 21, 45-59. [CrossRef]

45. Fu, K.; Moreno, D.; Yang, M.; Wood, K.L. Bio-Inspired Design: An Overview Investigating Open Questions From the Broader Field of Design-by-Analogy. J. Mech. Des. 2014, 136, 1-18. [CrossRef]

46. Wilson, J.O.; Rosen, D.; Nelson, B.A.; Yen, J. The effects of biological examples in idea generation. Des. Stud. 2010, 31, 169-186. [CrossRef]

47. Hesselberg, T. Biomimetics and the case of the remarkable ragworms. Naturwissenschaften 2007, 94, 613-621. [CrossRef] [PubMed]

48. Helms, M.; Vattam, S.; Goel, A.K.; Yen, J. Enhanced understand of biological systems using StructureBehavior-Function models. In Proceedings of the Proceedings of the 2011 11th IEEE International Conference on Advanced Learning Technologies, Athens, GA, USA, 6-8 July 2011; pp. 239-243.

49. Johansson-Sköldberg, U.; Woodilla, J.; Çetinkaya, M. Design Thinking: Past, Present and Possible Futures. Creat. Innov. Manag. 2013, 22, 121-146. [CrossRef]

50. Brown, T. Design Thinking. Harv. Bus. Rev. 2008, 86, 252.

51. Kelley, T. Prototyping is the Shorthand of Design of innovation. Des. Manag. J. 2001, 12, 35-42.

52. Pei, E.; Campbell, I.; Evans, M. A taxonomic classification of visual design representations used by industrial designers and engineering designers. Des. J. 2011, 14, 64-91. [CrossRef]

53. Holmquist, L.E. Prototyping: Generating Ideas or Cargo Cult Designs? Interactions 2005, 48-54. [CrossRef]

54. Goldschmidt, G. To see eye to eye: The role of visual representations in building shared mental models in design teams. CoDesign 2007, 3, 43-50. [CrossRef]

55. Porter, M.M.; Ravikumar, N.; Barthelat, F.; Martini, R. 3D-printing and mechanics of bio-inspired articulated and multi-material structures. J. Mech. Behav. Biomed. Mater. 2017, 73, 114-126. [CrossRef] [PubMed]

56. Frølich, S.; Weaver, J.C.; Dean, M.N.; Birkedal, H. Uncovering Nature's Design Strategies through Parametric Modeling, Multi-Material 3D Printing, and Mechanical Testing. Adv. Eng. Mater. 2017, 19, 1-8. [CrossRef] 
57. Reichert, S.; Schwinn, T.; La Magna, R.; Waimer, F.; Knippers, J.; Menges, A. Fibrous structures: An integrative approach to design computation, simulation and fabrication for lightweight, glass and carbon fibre composite structures in architecture based on biomimetic design principles. CAD Comput. Aided Des. 2014, 52, 27-39. [CrossRef]

58. Hsiung, B.-K.; Shawkey, M.D.; Blackledge, T.A. Blue tarantulas and dancing rainbow spiders inspire new color technologies (Conference Presentation). In Proceedings of the SPIE Smart Structures and Materials + Nondestructive Evaluation and Health Monitoring, Portland, OR, USA, 25-29 March 2017; Volume 10162.

59. Van Daal, L. Biomimicry; 3D Printed Soft Seat. Available online: https://www.lilianvandaal.com/biomimicry3d-printed-soft-seat (accessed on 28 May 2019).

60. Ivankova, N.V.; Creswell, J.W.; Stick, S.L. Using Mixed-Methods Sequential Explanatory Design: From Theory to Practice. Field methods 2006, 18, 3-20. [CrossRef]

61. Collins, K.M.T. Advanced sampling designs in mixed research: Current practices and emerging trends in the social and behavioral sciences. In Sage Handbook of Mixed Methods in Social and Behavioral Research; Teddlie, A.T.C., Ed.; Sage: Thousand Oaks, CA, USA, 2010; pp. 353-377.

62. Agresti, A. An Introduction to Categorical Data Analysis, 2nd ed.; Wiley: Hoboken, NJ, USA, 2007.

63. Kvale, S. Analyzing interviews. In SAGE Research Methods; Sage Publications: London, UK, 2007; pp. $102-120$.

64. Miles, M.B.; Huberman, M.A.; Saldana, J. Drawing and Verying Conclusions. In Qualitative Data Analysis: A Methods Sourcebook; Sage Publications: Thousand Oaks, CA, USA, 2014; pp. 275-322.

65. Cohen, J. Statistical Power Analysis for the Behavioral Sciences, 2nd ed.; Routledge: New York, NY, USA, 2013.

66. Vincent, J.F.V.; Bogatyreva, O.A.; Bogatyrev, N.R.; Bowyer, A.; Pahl, A.-K. Biomimetics: Its practice and theory. J. R. Soc. Interface 2006, 3, 471-482. [CrossRef] [PubMed]

67. Vattam, S.S.; Goel, A.K.; Rugaber, S.; Hmelo-silver, C.E.; Gray, S.; Sinha, S. Understanding Complex Natural Systems by Articulating Structure-Behavior- Function Models. J. Educ. Technol. Soc. 2011, 14, 66-81.

68. Chan, J.; Schunn, C. The impact of analogies on creative concept generation: Lessons from an in vivo study in engineering design. Cogn. Sci. 2015, 39, 126-155. [CrossRef]

(C) 2019 by the authors. Licensee MDPI, Basel, Switzerland. This article is an open access article distributed under the terms and conditions of the Creative Commons Attribution (CC BY) license (http://creativecommons.org/licenses/by/4.0/). 